\title{
The effect of supportive nursing intervention on burden and coping strategies of cargivers of children with cancer
}

\author{
Ghada Ahmed Hassan, Hanady Shaaban Ibrahim \\ Faculty of Nursing, Menoufia University, Menoufia, Egypt
}

Received: November 16, 2017

Accepted: January 24, 2018

Online Published: March 27, 2018

DOI: $10.5430 /$ jnep.v8n7p125

URL: https://doi.org/10.5430/jnep.v8n7p125

\begin{abstract}
Background and objective: Cancer is a serious health problem. Children with cancer are in particular need of support and care due to its complications followed by chemotherapy. These children should be cared for at home by family caregivers, and this places great mental and physical burden on caregivers. Therefore, appropriate and effective nursing interventions are essential in order to decrease burden and improve their coping pattern. The aim of this study was to determine the effect of supportive nursing intervention on the burden of care and coping pattern in caregivers of children with cancer.

Methods: Research design: A Quasi-study pre, immediately after, and 1 month after the intervention was used to test the study hypothesis and fulfill the aim of the study. Setting: The study was conducted at outpatient clinic in Specialized Pediatric Hospital at Benha City. Subjects: Sixty caregivers for children with cancer was chosen through convenient sampling method and divided by using table of random numbers into two groups, study and control group. Caregivers of the study group attended seven nursing intervention sessions. Tools: The tools used were (1) An inertviewing questionnaire which include two part; sociodemoghaphic date and medical history for child and thier caregivers (2) Zarit Burden Scale (3) Coping Health Inventory for caregivers parents (CHIP).

Results: During the study period, burden decreased in the study group and increased in the control group. Mean burden of care score before, immediately after, and 1 month after the intervention was 42.2, 33.7, and 25.6, respectively, in the study group and 44.2, 46.1, and 48.5, respectively, in the control group. In addition, the mean burden score in the study group significantly decreased in comparison with the control group $(p<.001)$. Also, coping strategies increased in the study group and decreased in the control group. Mean coping pattern score before, immediately after, and 1 month after the intervention was 32.8, 47.5, 53.6, respectively, in the study group and 34.7, 30.7 and 26.2, respectively, in the control group. In addition, the mean coping pattern score in the study group significantly improved in comparison with the control group $(p<.001)$.

Conclusions: The supportaive nursing intervention can decrease burden in caregivers of children with cancer and consequently improve their methods of coping.
\end{abstract}

Key Words: Burden, Coping pattern, Supportive nursing intervention, Children with cancer

\section{INTRODUCTION}

Cancer is the second cause of death in children from age 5 to 14 . The first year of life to less than five years of age is considered the peak incidence of cancer. In developed countries only $0.5 \%$ and world wide about half of all the childhood cancer cases diagnosed before 15 years of actually Egypt.

*Correspondence: Ghada Ahmed Hassan; Email: ghada_ahmed1982@yahoo.com; Address: Faculty of Nursing, Menoufia University, Menoufia, 
occur below the age of 5 years. ${ }^{[1]}$ Each year the prevelance of childhood cancers represent less than $1 \%$ of all cancers diagnosed. In the united stated about 10.270 children under the age of 15 will be diagnosed with cancer in 2017. ${ }^{[1]}$ In Egypt, annually the incidence rate of children with cancer is about 150 cases/per million children from age of (birth-14 years)..$^{[2]}$

Mostly care of children with cancer ocurr at home by family and family caregivers. Researches have demonstrated that children with cancer are considerable burden not only on the child but also on the family as a whole. ${ }^{[3]}$ Caregiver burden is defined as the strain by a person who cares for chronically ill. It is a multidimensional response to physical, psychological, emotional, social, and finicial stressors associated with the caregiving experience. Evidence shows that caregivers of cancer children have negative impact on their health and wellbeing and experience diminished quality of life. A caregiver has responsabilities to not only look after the child chronic illness but also to make adjustments to his or her life. ${ }^{[4]}$

Nurses spend a long period of time in caring of cancer children and with their caregivers. Therefore, nurses should facilitate and encourage open communication a bout caregiver needs, feelings, and concerns related to cancer survivor adherence to treatment regimens, also they teach caregivers how to care factors that will mediate a positive adjustment and outcome. ${ }^{[5,6]}$ Nursing care should be coordenated to meet child physical and psychological needs while involving the family when appropriate. Nurses have a unique position to identify stress and the psychological burden of caregivers, and the appropriate and effective interventions required to reduce the burden on caregivers and consequentely their methods of coping. ${ }^{[7]}$

\subsection{Significance of the problem}

Cancer is a serious health problem. Nurses should recognize the possible negative effects of cancer such as decresed familial coping and adaptation, abilities, and incresed family stress levels. The caregiver needs appropriate interventions to help him in reliving the burden to fulfill his role. ${ }^{[8]}$ Interventions aimed at reducing the caregiver's burden should focus on enhancing their functional role and family support. ${ }^{[9]}$ Four major stratiges of interventions for family caregivers are eucation, social support, counseling and multi-component programs. ${ }^{[10]}$ So, caregivers-focused intervention programs that provide a combination of information about illness, family support, crisis intervention and adaptation strategies (adaptive behavior and problem-solving skills), access to supportive resources, and self-care. ${ }^{[11]}$ Studies and interventions that have been conducted on caregivers of cancer patients especially children with cancer are limited in number. Com- prehensive support, including physical, emotional, mental, and spiritual as a whole require special attention from the studies. ${ }^{[12]}$ For this reaseon, the researchers aimed to conduct a research to study the effect of a supportive nursing intervention on the burden and coping pattern of caregivers of children with cancer.

\subsection{Aim of the study}

The purpose of the current study was to evaluate the effect of supportive nursing intervention on the burden of care and coping pattern in caregivers of children with cancer.

\subsection{Hypothesises}

(1) The caregivers of children with cancer who received supportive nursing intervention were more likely to have fewer burdens than those who did not receive the intervention.

(2) The coping pattern of caregivers of children with cancer who received supportive nursing intervention will be improved than those who did not receive the intervention.

\section{SUBJECTS AND METHODS}

\subsection{Study design}

The study was utilized using a Quasi-study pre-immediately after and one month after the intervention.

\subsection{Study setting}

This study was carried out at outpatient clinics from Specialized Pediatric Hospital at Banha City.

\subsection{Study subjects}

A convenience sample of 60 cargivers of children with cancer who are attending the above mentioned setting over 6 months period was obtained. This number by using table of random numbers, were assigned as follow:

Group I: The study group consisted of 30 caregivers of children with cancer who enrolled in the supportive nursing intervention

Group II: The control group consisted of 30 caregivers of children with cancer. This group received the usual care in hospital only.

\subsection{Inclusion criteria}

(1) Being the main caregiver of child medically diagnosed with cancer and undergoing chemotherapy.

(2) Over 18 years of age.

(3) Lack of mental illnesses.

(4) Able to speak, read and write in arabic.

(5) Not participating in any other similar studies. 


\subsection{Exclusion criteria}

(1) When they did not attend more than two supporative nursing intervention sessions.

(2) Had an acute and chronic physical disease that prevented them from caring their children.

(3) If their children died during the period of the study.

\subsection{Tools of data collection}

Three tools were used for data collection,

- Tool I: An interviewing questionnaire.

- Tool II: Zarit Burden Inventory (ZBI).

- Tool III: Coping Health Inventory for Parents (CHIP).

Tool I: An interviewing questionnaire which included two part: part (a) sociodemographic data for child which included ( age, sex, level of education,place of residance, rank of the child) and their caregiver (main caregiver, age, occupation, income, level of education). And part (b) which included medical history for the child (medical diagnosis, period of disease) and their caregiver (present medical history).

Tool II: The Zarit Burden Inventory (ZBI): The tool of Zarit et al. (1986) ${ }^{[13]}$ was used to measure to what extent the family caregiver have physical, social, and psychological burden as a result of caring children with cancer.

Tool III: CHIP developed by McCubbin, Nevin, and Cauble in $1981^{[14]}$ was used to measure caregivers coping strategies.

\subsection{Procedures}

The study was executed according to the following steps:

(1) An official letter from the Faculty of Nursing, Menoufia University was forwarded to the director of specialized pediatric hospital to take his permission to collect data after explaining the purpose of the study.

(2) Tool I was developed by the researchers after extensive review of recent and related literature.

(3) Tool II was modified by Amar $(2015)^{[15]}$ by adding 8 questions regarding physical, and psychological burden to suitable for Egyptian culture. The modified ZBI tool contained 29 items that consisted of three main section physical stress contain four question, social stress contain ten question and psychological stree contain fifteen questions, these items were scored according to 3-point likert scale never (0), sometimes (1), and always used (2). The total of points gained by the caregivers (with scores ranging from 0 to 58) showed the amount of stress and burden of care experienced by them. ${ }^{[15]}$ Scores arranged as the following grade, mild from 0-19, moderate: more than 19-less than 38 and severe from $38-58$.

Published by Sciedu Press
(4) Tool III: The CHIP is a parental self-report instrument consisting of a checklist of 44 specific behaviors. It has three subscales that represent different positive coping pattrens (Pattern I was identified as maintaining family integration, cooperation and an optimistic of the situation is made up of 16 items reflecting behaviours that focus on the family and the parent's view on life and the child's illness. Pattern II was identified as maintaining social support, self-esteem and psychological stability is composed of 19 items reflecting parental efforts to have a personal sense of well-being by obtaing social support from others, maintaing feeling of self-esteem, and dealing with psychologial tensions and strains. Ranging from 0 to 88). Pattern III was identified as understanding the medical situation through communication with other parents and consultation with medical staff is composed of 9 coping behaviors focusing on the interface between parents or caregivers and healthcare personnel, as well as other parents or caregivers in similar situation. This validated instrument was designed to assess parents' or caregivers' appraisal of behaviors currently in use to manage family life when they have a seriously ill or chronically ill child, this tool was modified by the reserchers in this study by translating it into Arabic, rephrasing the sentences to be suitable for Egyptian language and culture. The scoring also has been modified to be 3-point likart scale instead of 5-point likerat scale as the following: never (0), sometimes (1), and always used (2). The total of points gained by the caregivers. Scores arranged as the following grade, mild from 0-29, moderate: more than 29-less than 58 and severe from 58-88. The caregivers completed this questionnaire before, immediately after (after the seven nursing intervention sessions), and 1 month after the intervention.

(5) Validity of the tools: The tools were validated by a jury of three experts in community, pediatric and psychiatric health nursing specialty to ascertain relevance and completeness and the required modification was carried out accordingly.

(6) Reliability of the tools: Tools' reliability was done for zarit burden interviewing questionnaire the reliability of the tool was done to determine the extent to which items in the questionnaire were related to each other by Cronbach's Co-efficiency Alpha $(\alpha=0.97)$. Pearson correlation coefficiency was done to test the internal consistency $(r=0.02$ - 0.98) of all items of the questionnaire. Concerning CHIP, reported internal reliability for all subscales range from 0.80 to 0.93 .

(7) A pilot study was carried out on 5 participants (excluded from the study subjects) from the previously mentioned settings to assure feasibility of the study, clarity and applicability of the tools and to identify obstacles that might interfere 
with the process of data collection. Tools were modified accordingly prior to data collection.

(8) For each recruited participant the following issues were considered: a written informed consent was obtained from all participants. Keeping their right to withdrawal at any time as well as assuring confidentialty of their data.

(9) The 60 participants who met the inclusion criteria divided into two group, study group and control group. The study group received the supportive nursing intervention while control group received the routine hospital care.

(10) The supportive nursing intervention was implemented during six months, the field work started in November 2016 to April 2017, and follow up was carried out after one month in May 2017.

(11) Implementation of the study passed into three phases (pre assessment phase, implementation phase and post assessment phase). Pre assessment phase: A comfortable and private place was chosen for the Interview. Orientation was done about purpose of the study, significance, content. Each participants of both groups was individually interviewed in outpatient clinics while they waiting their children to take chemotherapy.

(12) Implementation phase: The researchers arranged the intervention sessions based on the needs assessment conducted according to the view of specialists in this area and a survey of children' caregivers done in this hospital, and through interviews with the participants and reviewed studies in this regard. This supportive nursing intervention was developed and given through sessions. Each session has a general objective and set of specific objectives. The researchers divided the study group into 8 groups' each group consisted of 3-5 caregivers, the participants of the study attending the hospital for taking chemotherapy dose every 21 days. The supporative nursing intervention used has been sequenced through the seven sessions; sessions started according to cargivers' suitable time, usually at $9 \mathrm{Am}$, twice days per week, the duration of each session was ranged from 60-90 minutes including periods of discussion according to caregivers' achievement, progress and feedback in groups. A simple breakfast was available as motivations for the participants. Methods of teaching include lectures, question and answer, and role playing, and techniques such as brainstorming, group discussion, and small groups were used. At the beginning of the first session of the program the telephone number of the researchers and participants were available to each others. Caregivers were oriented regarding the program contents, its purpose and its impact; and caregivers were informed about the time of the next session. Each session started by a summary about what has been discussed in the previous session and the objectives of the new session, using simple Arabic language was used to suit the caregivers' level of understanding. The session ended by a summary of its contents and feedback from the caregivers to ensure that they have got the maximum benefit.

(13) Supportive nursing intervention program content is summarized as follows:

- First session: Introducing the caregivers to the researchers and setting plans and goals, and question and answer;

- Second session: Providing information on cancer, types and manifestation of cancer, predisposing factors and investigation of childhood;

- Third session: Identify type of cancer treatment, determine side effect of chemotherapy, preparation before and after chemotherapy session and importance of follow-up and care of children;

- Fourth session: Determine the nutritional requirements that should be given to the child, providing methods to protect their children at home;

- Fifth session: Providing information about self-care, time management and strengthening the social dimension and social interactions of the caregivers;

- Sixth session: Providing information on problemsolving skills, decision making skills and stress management strategies to improve coping and adaptation with disease to reduce stress and anxiety in caregivers;

- Seventh session: Strengthening their spiritual dimension.

(14) In the final session, a booklet containing relaxation, and stress and anger management techniques, and educational booklets on the content of each session in summary were prepared and provided for the study participants. Furthermore, for spiritual intervention, a religious expert helped. In addition, for 1 month after the intervention, the study caregivers were held for follow up and refreshing information. Also, they were given advice based on their needs via telephone, and if needed, they were referred to the assistance unit or psychiatrist specialists.

(15) Post assessment phase.

(16) At the end of the intervention, immediate post test was taken after the last session and another posttest was taken after one month of intervention, the time from intervention to another posttest, the researchers follow the participants by telephone in order to assure on the intervention guidelines.

(17) Posttest was collected from educated caregivers (having technical and high education) by themselves but, for the 
illiterate education was collected by the researchers.

(18) The booklet of intervention were distributed for all attendant caregivers and give copies of it for nurses for helping other caregivers.

\section{Results}

Data were entered and analyzed using SPSS (Statistical Package for Social Science) statistical package version 22. Graphics were done using Excel program. Quantitative data as total score of burden of care as well as the total score of its components: physical, social \& psychological were presented by mean $(\bar{X})$ and standard deviation (SD). It was analyzed using student $t$-test for comparison between two means, and Two-Way Repeated Measures ANOVA (mixed design) for comparison of mean and SD of each type of, as well as total score of, burden between the three levels of intervention (before intervention, immediately after intervention, and 1 month after intervention) in both the study group, and control. Qualitative data were presented in the form of frequency distribution tables, number and percentage. It was analyzed by chi-square $\left(\chi^{2}\right)$ test. However, if an expected value of any cell in the table was less than 5, Fisher Exact test was used (if the table was 4 cells), or Likelihood Ratio (LR) test (if the table was more than 4 cells). Level of significance was set as $p$ value $<.05$ for all significant tests.

Table 1. Demographic characteristics of children with cancer in the study and control groups

\begin{tabular}{|c|c|c|c|c|c|c|c|c|}
\hline \multirow{2}{*}{\multicolumn{2}{|c|}{ Demographic characteristics }} & \multirow{2}{*}{\multicolumn{2}{|c|}{$\begin{array}{l}\text { Group } \\
\text { Cases }\end{array}$}} & & & \multicolumn{2}{|c|}{ Total } & \multirow{3}{*}{$\chi^{2} \& p$ value } \\
\hline & & & & $\mathrm{Co}$ & & \multirow{2}{*}{ N. } & \multirow{2}{*}{$\%$} & \\
\hline & & $\mathbf{N}$ & $\%$ & $\mathbf{N}$ & $\%$ & & & \\
\hline \multicolumn{9}{|l|}{ A-Children } \\
\hline \multirow{4}{*}{ Age } & $<4$ years & 10 & 47.6 & 11 & 52.4 & 21 & 35 & \multirow{4}{*}{$\mathrm{LR}^{*}=0.35, p=.93^{\mathrm{NS}}$} \\
\hline & 4 to $<8$ years & 12 & 52.2 & 11 & 47.8 & 23 & 38.3 & \\
\hline & 8 to $<12$ years & 5 & 55.6 & 4 & 44.4 & 9 & 15 & \\
\hline & 12 to $\leq 15$ years & 3 & 42.9 & 4 & 57.1 & 7 & 11.7 & \\
\hline \multirow{2}{*}{ Sex } & Male & 19 & 63.3 & 20 & 66.7 & 39 & 65 & \multirow{2}{*}{$\chi^{2}=0.07, p=.78^{\mathrm{NS}}$} \\
\hline & Female & 11 & 36.7 & 10 & 33.6 & 21 & 35 & \\
\hline \multirow{3}{*}{ School stage } & Nursery & 22 & 73.3 & 22 & 73.3 & 44 & 73.3 & \multirow{3}{*}{$\mathrm{LR}^{*}=0.26, p=.88^{\mathrm{NS}}$} \\
\hline & Primary & 5 & 16.7 & 4 & 13.3 & 9 & 15 & \\
\hline & Preparatory & 3 & 10 & 4 & 13.3 & 7 & 11.7 & \\
\hline \multirow{2}{*}{$\begin{array}{l}\text { Place of } \\
\text { residence }\end{array}$} & Rural & 20 & 66.7 & 9 & 30 & 29 & 48.3 & \multirow{2}{*}{$\chi^{2}=8.1, p=.004^{\text {Sig. }}$} \\
\hline & Urban & 10 & 33.3 & 21 & 70 & 31 & 51.7 & \\
\hline \multirow{4}{*}{$\begin{array}{l}\text { Rank of the } \\
\text { child }\end{array}$} & Only & 3 & 10 & 3 & 10 & 6 & 10 & \multirow{4}{*}{$\mathrm{LR}^{*}=0.12, p=.98^{\mathrm{NS}}$} \\
\hline & First & 8 & 26.7 & 7 & 23.3 & 15 & 25 & \\
\hline & Middle & 9 & 30 & 10 & 33.3 & 19 & 31.7 & \\
\hline & Last & 10 & 33.3 & 10 & 33.3 & 20 & 33.3 & \\
\hline \multirow{4}{*}{$\begin{array}{l}\text { Medical } \\
\text { diagnosis }\end{array}$} & Leukemia & 0 & 0 & 18 & 60 & 18 & 30 & \multirow{4}{*}{$\chi^{2}=26.0, p=.000^{\mathrm{HS}}$} \\
\hline & Lymphoma & 10 & 33.3 & 4 & 13.3 & 14 & 23.3 & \\
\hline & Willim's tumor & 10 & 33.3 & 3 & 10 & 13 & 21.7 & \\
\hline & Others $^{*}$ & 10 & 33.3 & 5 & 16.7 & 15 & 25 & \\
\hline \multirow{2}{*}{$\begin{array}{l}\text { Period of } \\
\text { disease }\end{array}$} & $<4$ years & 12 & 40 & 13 & 43.3 & 25 & 41.7 & \multirow{2}{*}{$\chi^{2}=0.1, p=.79^{\mathrm{NS}}$} \\
\hline & 4 to $<8$ years & 18 & 60 & 17 & 56.7 & 35 & 58.3 & \\
\hline
\end{tabular}

${ }^{*} \mathrm{LR}=$ likelihood Ratio

As shown in Table 1, the distribution of the children regarding sociodemographic and medical history of disease reveals that the majority of age on both group betwean 4 to 8 years and more than half of studied cancer children were residence in urban areas $(51 \%)$ of both groups and majority of them were leukemia (30\%), lymphoma $(23.3 \%)$ of both group. There was no statsitically significant difference between the control group and study groups in terms of gender, educational level of children and the duration of illness $(p>.05)$

Table 2 shows the distribution of the studied caregivers regarding sociodemographic and their medical history of dis- 
ease, reveals that more than ninety percent of main caregivers were mothers in both groups and $65 \%$ of the total caregivers their age ranged from 30 to $>35$ years. More than one third $(38.3 \%)$ of studied caregivers were technical education and high education represented thirty five percent. Ninety percent of mothers of studied cancer children of both group don't work, more than two third $(66.7 \%)$ of both groups have enough incom.

Table 2. Demographic characteristics of caregivers of children with cancer with cancer in the study and control groups

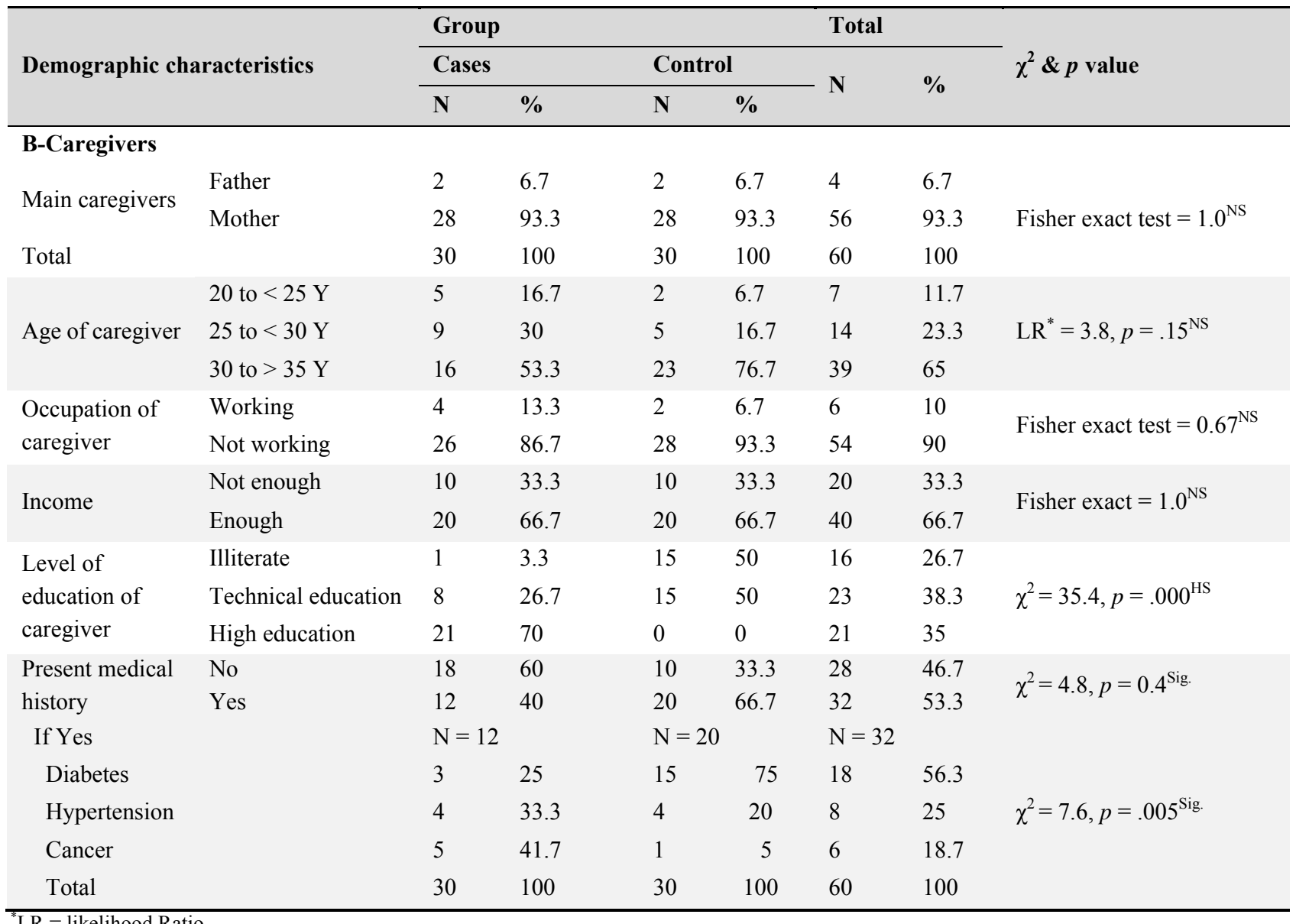

${ }^{*} \mathrm{LR}=$ likelihood Ratio

\subsection{Effect of supportive nursing intervention on burden of care}

As shown in Table 3 and Figures 1, 2, a mixed design twoway repeated measures ANOVA was conducted to evaluate the null hypothesis that there is no change in participants' burden of care (its components: physical, social, \& psychological, and total scores) when measured before, immediately post, and one month after supportive nursing intervention, in both study $(\mathrm{N}=30)$ and control groups $(\mathrm{N}=30)$. The results of the ANOVA indicated a statistically significant effect on decreasing burden of care among study group, $\mathrm{F}(2$, $57)=79.1, p=.000$, and partial Eta squared $\left(\eta^{2}\right)=0.74$ which denoted a high effect size of the supportive nursing intervention on decreasing the burden of care among caregivers. Follow up comparisons indicated that each pairwise difference was significant $(p=.000)$. There was a significant decrease in scores over time, suggesting that participation in the study group decreased caregivers' physical, social, and psychological burden of care for cancer children. Thus there is a significant evidence to reject the null hypothesis.

Figure 1 represents that the majority of caregivers in both group have high burden $(42.2 \%$ and $44.2 \%$ in study and control group) pre supportive nursing intervention which decresed to $33.7 \%$ and $25.6 \%$ immediately and after one month after intervention compaired to control group the burden was incresed to $46.1 \%$ and $48.5 \%$ immediately and after one month after intervention. This mean that the total burden of care among study group have decreased immediately and one month after the intervention while in the control group the burden have increased immediately and one month after the intervention. 
Table 3. The effect of supportive nursing intervention on the burden of care in caregivers of children with cancer

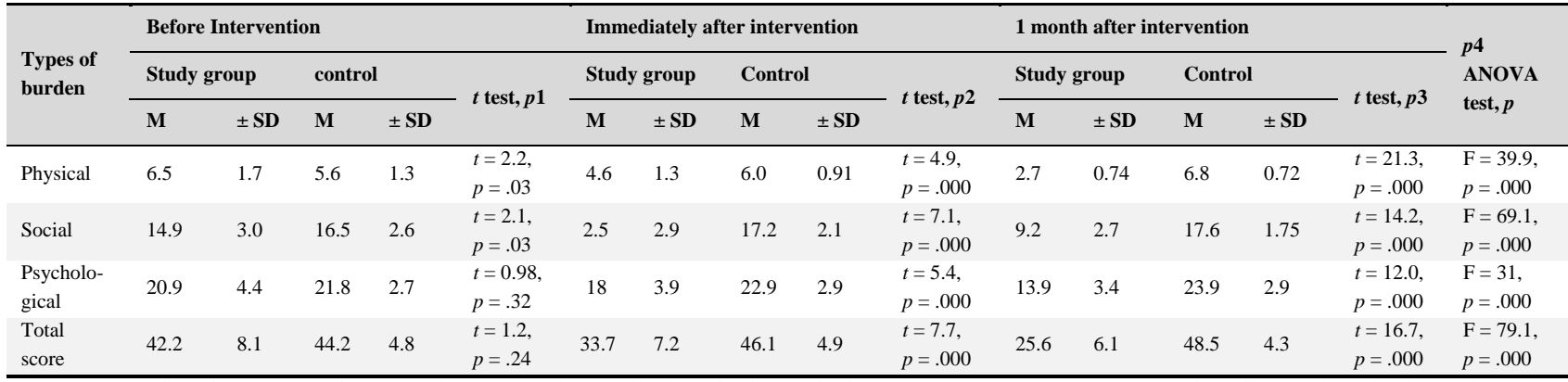

Note. $p 1$ = Comparison of mean and SD of each type of, as well as total score, of burden before intervention in the study and control groups. $p 2=$ Comparison of mean and SD of each type of, as well as total score, of burden immediately after intervention in the study and control groups. $p 3=$ Comparison of mean and SD of each type of, as well as total score, of burden 1 month after intervention in the study and control groups. $p 4$ = Two-Way Repeated Measures ANOVA (mixed design) for comparison of mean and SD of each type of, as well as total score, of burden between the three levels of intervention in both the study group, and control.

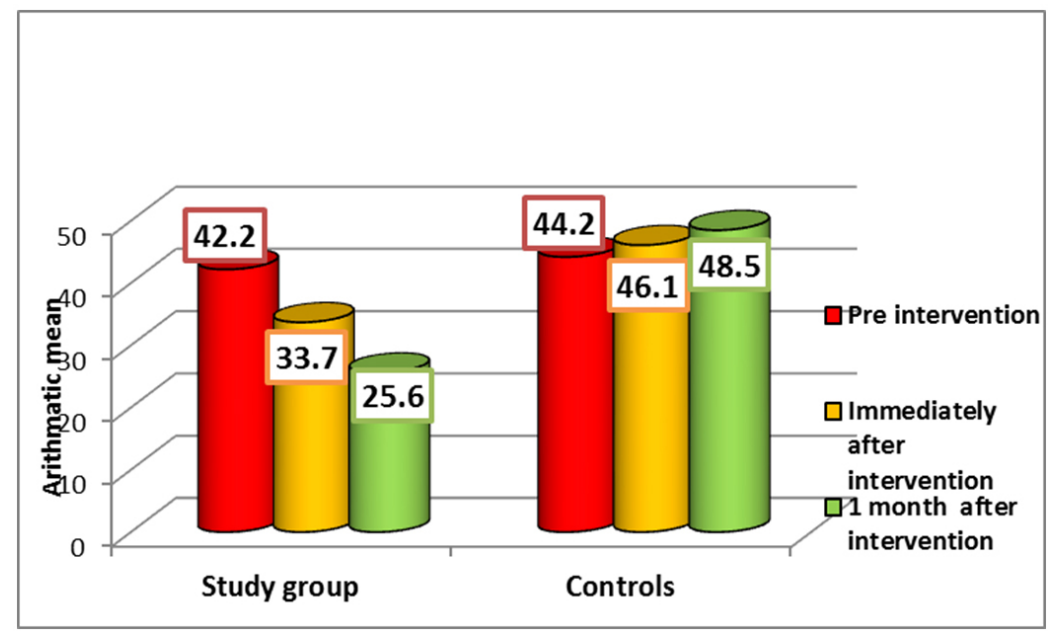

Figure 1. Effect of supportive nursing intervention pre, immediately and one month after the intervention on the level of burden among study and control group

Figure 2 represents that, the majority of studied caregivers vention, which decreased to $33.3 \%$ immediately after interhave severe burden in the study group $70 \%$ pre nursing inter- vention and to $20 \%$ at one month after the intervention.

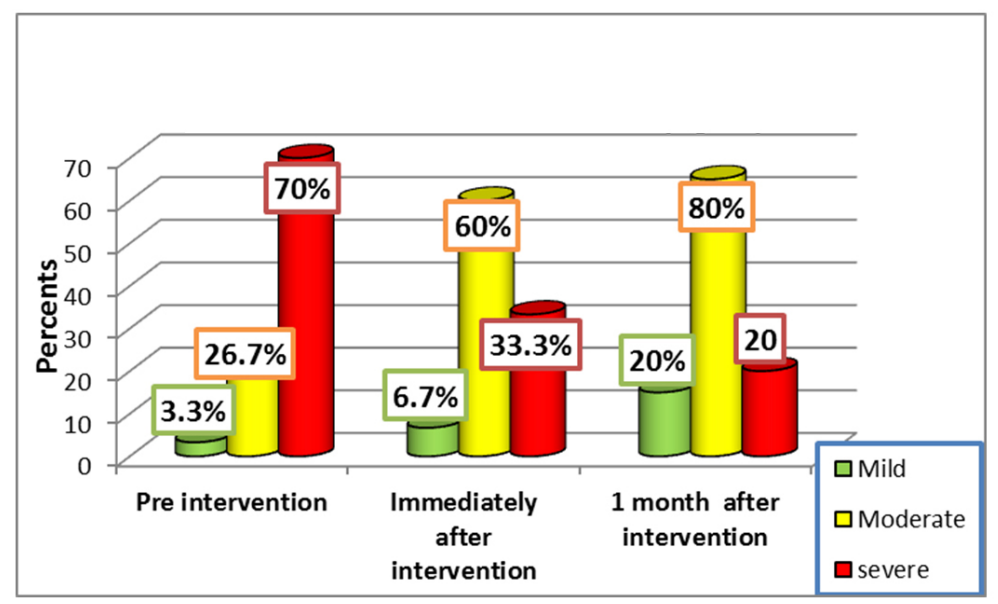

Figure 2. Effect of supportive nursing intervention pre, immediately and one month after the intervention on the grade of burden among study group 
Figure 3 shows that, the majority of studied caregivers have vention, which increased to $80 \%$ immediately after intervensevere burden in the control group $76.7 \%$ pre nursing inter- tion and to $90 \%$ at one month after the intervention.

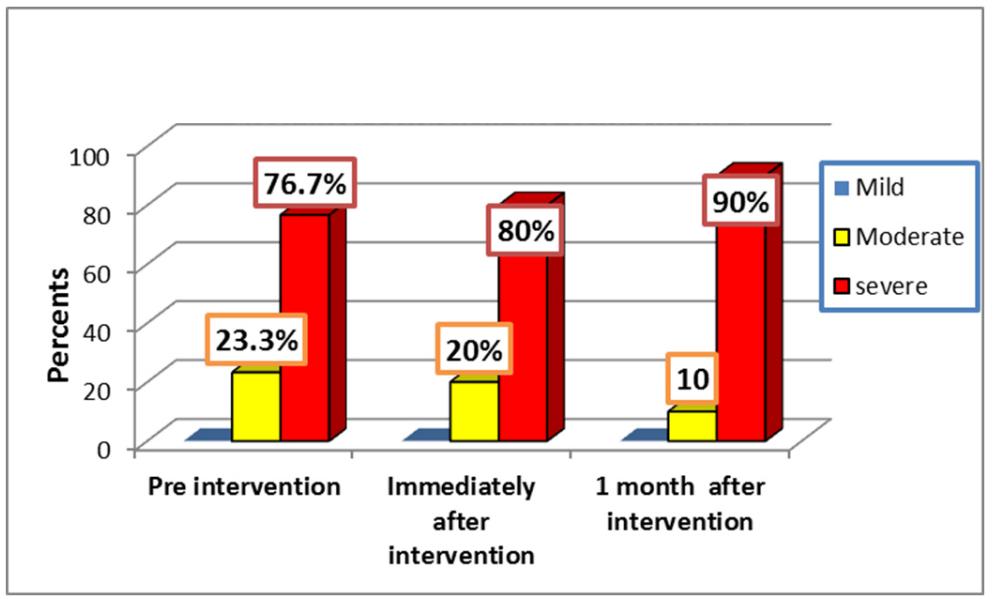

Figure 3. Effect of supportive nursing intervention pre, immediately and one month after the intervention on the grade of burden among control group

\subsection{Effect of supportive nursing intervention on coping} pattern among caregivers of children with cancer

As shown in Table 4, and Figures 3 and 4 a two-way repeated measures ANOVA (mixed design) was conducted to evaluate the null hypothesis that there is no change in participants' coping pattern of care (its components: maintaining family integration, maintaining social support \& self-esteem, understanding the medical situation, and total scores) when measured before, immediately post, and one month after supportive nursing intervention in both study $(\mathrm{N}=30)$ and control groups $(\mathrm{N}=30)$. The results of the ANOVA indicated a statistically significant effect on increasing the coping pat- tern of care among study group, $\mathrm{F}(2,57)=23.9, p=.000$, and partial Eta squared $\left(\eta^{2}\right)=.46$ which denoted a high effect size of the supportive nursing intervention on increasing the family cooperation of care among caregivers. Follow up comparisons indicated that each pairwise difference was significant $(p=.000)$. There was a significant increase in scores over time, suggesting that participation in the study group increased caregivers' maintaining family integration, maintaining social support \& self-esteem, and understanding the medical situation of care for cancer children. Thus there is a significant evidence to reject the null hypothesis.

Table 4. The effect of supportive nursing intervention on the coping pattern among caregivers of children with cancer

\begin{tabular}{|c|c|c|c|c|c|c|c|c|c|c|c|c|c|c|c|c|}
\hline \multirow{3}{*}{ Coping pattern } & \multicolumn{5}{|c|}{ Before Intervention } & \multicolumn{5}{|c|}{ Immediately after intervention } & \multicolumn{5}{|c|}{1 month after intervention } & \multirow{3}{*}{$\begin{array}{l}\text { ANOVA } \\
\text { test, P4 }\end{array}$} \\
\hline & \multicolumn{2}{|c|}{ Study group } & \multicolumn{2}{|c|}{ Control } & \multirow{2}{*}{$t$ test, $p 1$} & \multicolumn{2}{|c|}{ Study group } & \multicolumn{2}{|c|}{ Control } & \multirow{2}{*}{$t$ test, $p 2$} & \multicolumn{2}{|c|}{ Study group } & \multicolumn{2}{|c|}{ Control } & \multirow{2}{*}{$t$ test, $p 3$} & \\
\hline & $\mathbf{M}$ & \pm SD & $\mathbf{M}$ & \pm SD & & $\mathbf{M}$ & \pm SD & $\mathbf{M}$ & \pm SD & & $\mathbf{M}$ & \pm SD & $\mathbf{M}$ & \pm SD & & \\
\hline $\begin{array}{l}\text { Maintaining } \\
\text { Family } \\
\text { Integration }\end{array}$ & 12.0 & 2.8 & 13.1 & 3.1 & $\begin{array}{l}t=1.4 \\
p=.2^{\mathrm{NS}}\end{array}$ & 17.9 & 4.5 & 11.6 & 2.8 & $\begin{array}{l}t=6.5 \\
p=.000\end{array}$ & 20.1 & 4.4 & 9.4 & 2.1 & $\begin{array}{l}t=11.9 \\
p=.000\end{array}$ & $\begin{array}{l}\mathrm{F}=39.9, \\
p=.000\end{array}$ \\
\hline $\begin{array}{l}\text { Maintaining } \\
\text { Social support } \\
\text { \& Self-esteem }\end{array}$ & 14.7 & 4.3 & 14.5 & 2.9 & $\begin{array}{l}t=0.21, \\
p=.83^{\mathrm{NS}}\end{array}$ & 19.5 & 4.6 & 12.3 & 2.7 & $\begin{array}{l}t=7.2 \\
p=.000\end{array}$ & 21.3 & 4.2 & 10.4 & 2.2 & $\begin{array}{l}t=12.4 \\
p=.000\end{array}$ & $\begin{array}{l}\mathrm{F}=69.1, \\
p=.000\end{array}$ \\
\hline $\begin{array}{l}\text { Understanding } \\
\text { the Medical } \\
\text { Situation }\end{array}$ & 6.4 & 2.4 & 7.5 & 3.1 & $\begin{array}{l}t=1.5, \\
p=.13^{\mathrm{NS}}\end{array}$ & 10.0 & 2.3 & 6.8 & 3.3 & $\begin{array}{l}t=4.4 \\
p=.000\end{array}$ & 12.1 & 2.2 & 6.3 & 2.7 & $\begin{array}{l}t=9.1 \\
p=.000\end{array}$ & $\begin{array}{l}\mathrm{F}=31, \\
p=.000\end{array}$ \\
\hline Total score & 32.8 & 7.9 & 34.7 & 7.5 & $\begin{array}{l}t=0.94 \\
p=.3^{\mathrm{NS}}\end{array}$ & 47.5 & 9.9 & 30.7 & 7.3 & $\begin{array}{l}t=7.4 \\
p=.000\end{array}$ & 53.6 & 10.1 & 26.2 & 6.3 & $\begin{array}{l}t=12.6 \\
p=.000\end{array}$ & $\begin{array}{l}\mathrm{F}=79.1, \\
p=.000\end{array}$ \\
\hline
\end{tabular}

Figure 4 represents that the coping pattern of caregivers in both group was $32.8 \%$ and $34.7 \%$ in study and control group pre supportive nursing intervention which increased to $47.5 \%$ and $53.6 \%$ immediately and after one month after intervention in study group compaired to decreased to $30.7 \%$ and $26.2 \%$ immediately and after one month after intervention. 
This mean that the total coping pattern among study group Figure 5 demonstrates that, the half of studied caregivers have improved immediately and one month after the inter- $50 \%$ have mild coping pre supportative nursing intervention, vention while in the control group the coping pattern have which increased to $32.3 \%$ high coping pattern immediately decreased immediately and one month after the intervention. and $33.3 \%$ one month after the intervention.

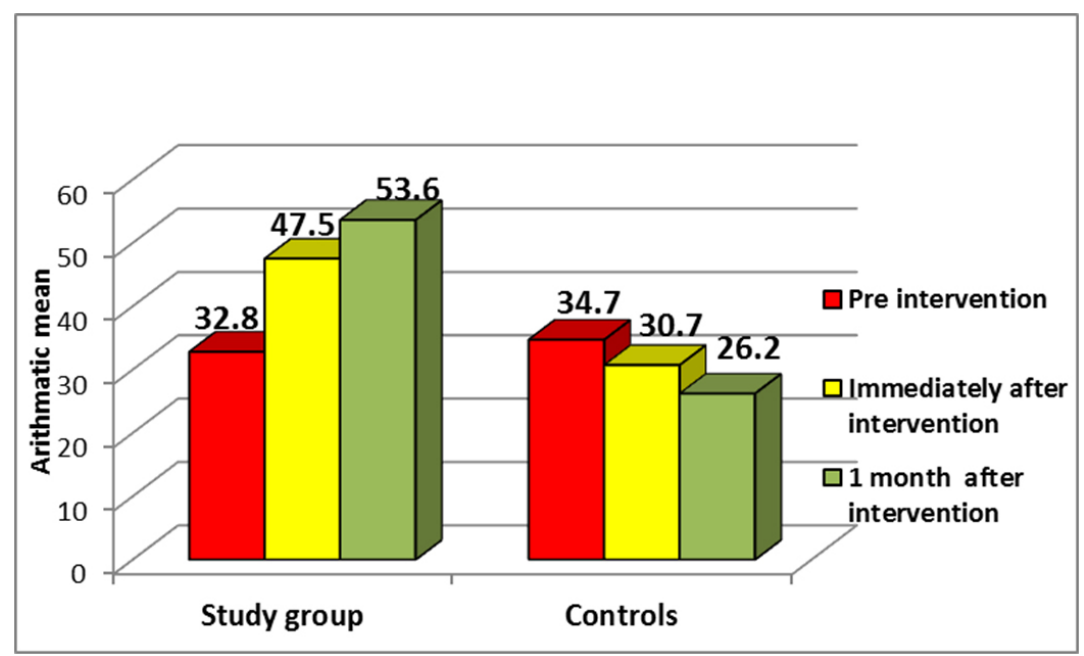

Figure 4. Effect of supportive nursing intervention pre, immediately and one month after the intervention on the level of coping pattern among study and control group

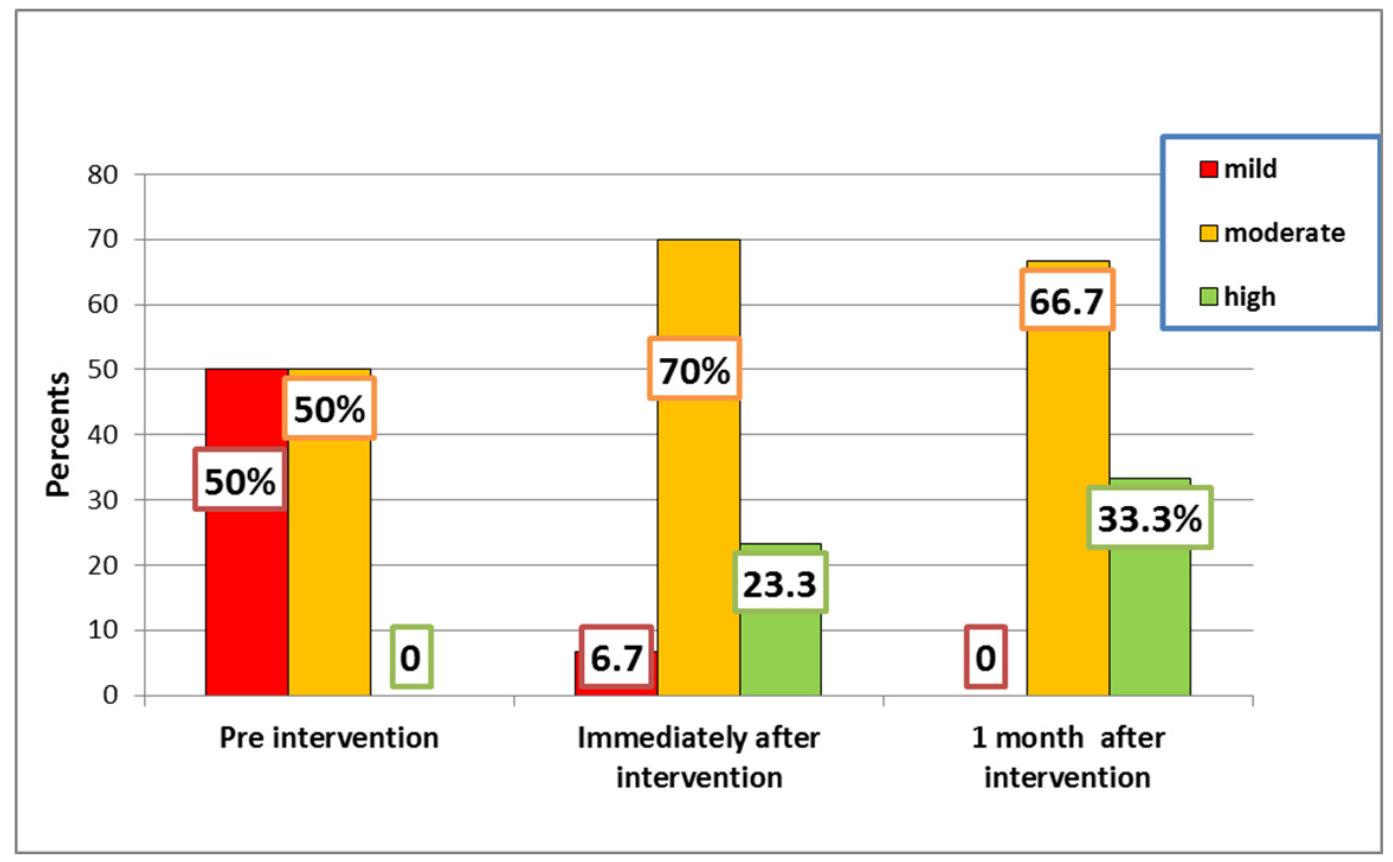

Figure 5. Effect of supportive nursing intervention pre, immediately and one month after the intervention on the grade of coping pattern among study group

Figure 6 demonstrates that the minorities of caregivers in which increased to $40 \%$ immediately and $60 \%$ one month the control group $16.7 \%$ have mild coping pre intervention, after the intervention. 


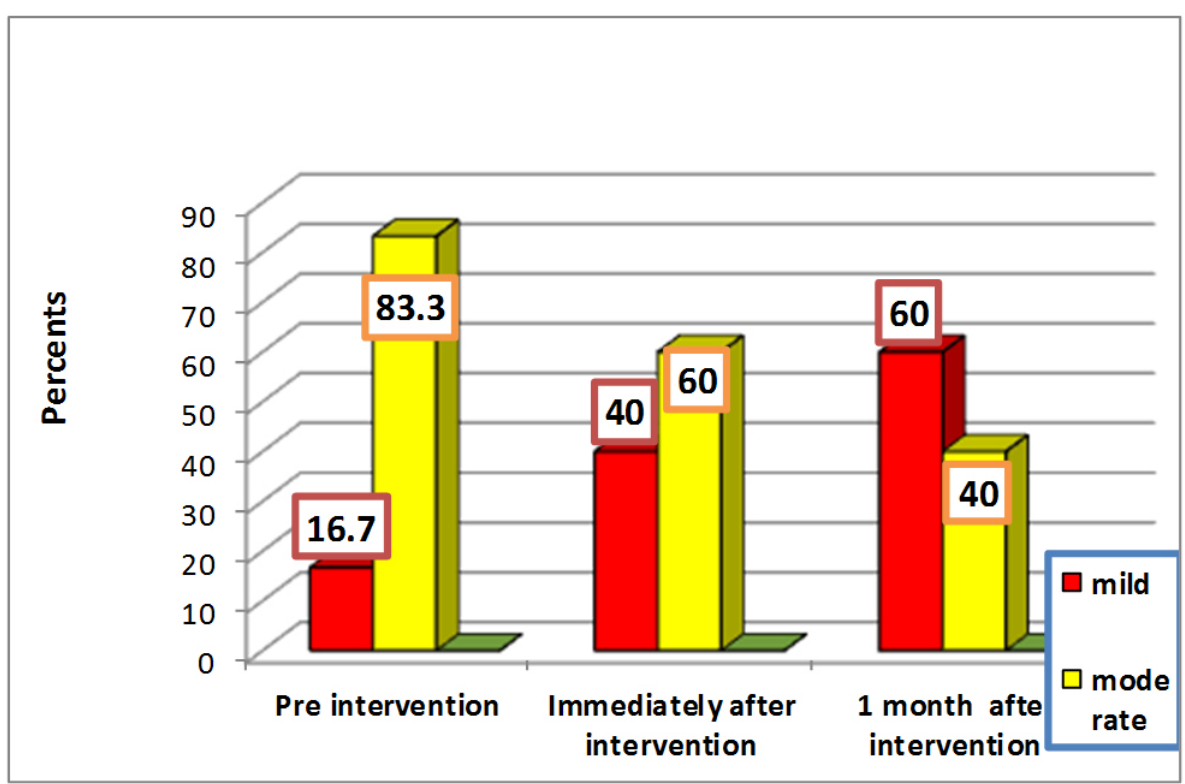

Figure 6. Effect of supportive nursing intervention pre, immediately and one month after the intervention on the grade of coping pattern among control group

\section{Discussion}

The present study confirmed that the caregivers who received supportive nursing intervention were more likely to have fewer burdens and improve their coping pattern than those who do not receive the supportive nursing intervention.

Regarding to feeling of burden among studied caregivers, the current study illustrated that there was statistically high significant difference in the study group than in control group and in the study group the burden was decrease during the periods of immediately after, and 1 month after the intervention. Moreover the majority of study group have severe burden reduced from $70 \%$ to $20 \%$ while in the control group increased from $76.7 \%$ to $90 \%$.

Moreover, the burden of care in these three time periods was significantly different. This finding agreed with Pahlavanzade, Khosravi and Moeini (2014) ${ }^{[16]}$ in their study about the effect of family based program on burden of caregivers of leukemia patients in Isfahan in 2013-2014. They found that the burden of care decreased after the supportive nursing intervention of the caregivers in the studied group. The results of the present study were also consistent with the study by Amer (2015) ${ }^{[15]}$ who studied the effect of nursing intervention on reducing burden of caregivers' for children with epilpepsy in Egypt and concluded that the burden of care had decreased after the nursing intervention.

Also, the result of this study was consistent with study conducted by Gazar et al. (2017) ${ }^{[17]}$ who studied the effectiveness of cognitive behavioral family intervention in reducing the burden of care in cares of patients with Alzhiemer's disease in Egypt they mentioned that the level of anxiety and satisfaction in the study group, compared to the control group, were significantly different after the intervention. This finding was consistent with El-Safty $(2016)^{[18]}$ who studied the effect of nursing intervention on traumatic stress and coping strategies among women with breast cancer in Egypt, he found that there were statistical differences between the study and control group regarding the level of post-traumatic stress and coping stategies post intervention.

Concerning the feeling of burden among caregivers, the presents study revealed that supportive nursing intervention including educational intervention for psychological support was decreased feeling of burden among caregiver.

The findings also showed that in all the time periods, except before implementing the intervention, there was a significant difference between the burden of care of study and control groups. Mean score of burden of care immediately after the intervention and 1 month after the intervention in the study group was significantly lower than in the control group. Belgacem et al.(2013) $)^{[11]}$ confirmed the results obtained in the present study who study the effectiveness of a training program on burden of care of cancer patients and their families. They found that the program decreased the burden of care for caregivers in the study group compared to the control group. Furthermore, burden of care in the study group was significantly lower than in the control group. Also, this finding was consistent with Toseland et al. $(2007)^{[19]}$ in the university of Texas at Austin School of Nursing about group intervention to support family caregivers. They found that 
intervention category, significantly reducing subjective burden. The researchers believed that the reason for the relative success of the supportive nursing intervention could be its content, which was designed based on reviewing problems identified in similar studies and needs assessment of caregivers' of studied cancer children. Moreover, in the present study, supportive nursing intervention by using individualized and group therapy which is more effective in comparison to individual learning method and follows up of care is very important.

On the other side, the current study is incongruent with study conducted by Zarit, Reever \& Bach-Peterson (2001) ${ }^{[20]}$ who studied dementia and the family: A stress management approach, in Texas. They found that interventions evaluated using the burden interview, showed no significant effect on burden of family. Also, the study by Greedle et al. (2012) ${ }^{[21]}$ who studied the effectiveness of a collaborative care program on the burden of care of the caregivers of cancer patients showed that the program had no impact on reducing caregivers' burden of care. The differences in methodology, especially the implementation of supporative nursing intervention, such as the intervention content, may explain this difference. The researchers believed that lack of similarities between the findings of this study and other similar studies can be related to the duration of the intervention and the disease type and that most Egyptians caregivers were women who report a decrease in burden by receiving psychological support. Another reason is that in Egypt, the financial burden is reduced for caregivers due to receiving insurance services. Another factor to be noted is that in the Egypt culture, spiritual support had significant effects on tolerating crisis, and other studies have not included this in their programs.

The current study revealed that supporative nursing intervention was effective in increasing coping strategies of studied caregivers. Maintaining family integration, cooperation and optimism, social support and psychological stability and communication with other parents and medical staff were strongly associated with reduced stress relating to overall family cohesiveness, the parent's perceptions of reward or satisfaction in caring for their child, and their concerns regarding their child in which many caregivers felt explaining their child's disability and specific difficulties to others are benefits. In general, caregivers reported the supportive nursing intervention is significant to alleviate stress. The result of current study was congruent with Amer, $(2015)^{[15]}$ who concluded that the coping strategies of caregivers were improved after intervention.

Also, this finding was consistent with El-Safty's (2016) ${ }^{[18]}$ study results revealed that, there were statistical differences

Published by Sciedu Press between the study and control group regarding the level of post-traumatic stress and coping strategies post intervention. In addition, the result of current study was congruent with study conducted by Asutin \& McDermott (2009) ${ }^{[22]}$ in USA who studied comparing coping (as measured by the CHIP) to parental attitude. They noted that improved attitude resulted in increased use of coping patterns; they suggested that the increased use of coping pattern strategies reflected a positive attitude of sharing feelings with others.

Caregivers who experience to higher level of burden would result in more frequent use of coping behaviors that make them to adjust and adapt to one's situation. Many of the nursing reserches in this area have explored those caregivers who were better able to cope with stressors and had perceived fewer burdens. ${ }^{[23,24]}$ In the same line of this explanation Damrosch \& Pert(2007) ${ }^{[25]}$ reported that in Turkey about self-reported adjustment, chronic sorrow, and coping of parents of children with chronic illness. Also, Blount et al. $(2008)^{[26]}$ who studied evidence - based intervention of coping and stress in pediatric psychology in University of Wales, Cardiff, they have referred to the importance of coping strategies in reducing stress for parents or caregivers.

Finally, nurses, psychologists and specialized professionals are in a unique position to develop more educative strategies aimed at improving the coping abilities and decreasing the burden of patients and their caregivers.

The limitations of this study could be the individual differences of the caregivers in respect to religious beliefs, spiritual and cultural values, and attitudes toward life that might have affected the amount of burden on caregivers. It was also possible that, during the intervention, the caregivers in the control and study groups have interacted with each other. On the other hand, they might have had access to information through sources such as mass media that can influence the caregivers' knowledge and burden. This matter was beyond the researchers' control.

\section{Conclusion}

Overall, the findings show that implementing the supportive nursing intervention is an effective mean in reducing the burden of care and consequently caregivers' methods of coping with the disease of their children.

Nevertheless, due to the limitations of this study, such as small sample size, limited time for the intervention, and thus, lack of long-term effectiveness follow-up, which was considered to be due to the intervention time limitation, these results cannot be generalized to the entire society. Therefore, further research is needed in this regard in order to confirm the positive effect of this supportive nursing intervention on 
the burden of care giving and coping strategies.

\section{Recommendation}

A comprehensive burden and coping pattern must be considered as an essential part of cancer children caregivers' during regular medical clinic follow up period. Caring for family caregivers of cancer children by providing supportive nurs- ing intervention to provide physical, emotional, social and financial support to reduce their burden and improve coping pattern must be considered as apriority for caregiver support.

\section{CONFlicts OF INTEREST Disclosure}

The authors declare that there is no conflict of interest.

\section{REFERENCES}

[1] American Cancer Society. Key statistics for childhood cancers. 2017. Available from: http://cancer.org. cancer

[2] Elattar LA, Ali-Eldin NH, Moneer MM, et al. Cancer Statistics for Children Age less than 20 years. National Cancer Institute, Cairo. 2009.

[3] Mack JW, Hilden JM, Watterson J, et al. Parent and physician perspectives on quality of care at the end of life in children with cancer. J Clin Oncol. 2005; 23: 9155-61. PMid:16172457 https: //doi.org/10.1200/JC0.2005.04.010

[4] Fitzmaurice C. Burden of cancer in the Eastern Mediterranean Region. 2005-2015: Findings from the Global burden of Disease 2015 study. International Journal of Public Health. 2017; 1-14.

[5] Epstein RM, Street RL. Patient-centered communication in cancer care: promoting healing and reducing suffering. National Cancer Institute, NIH Publication. Bethesda, MD, USA. 2007.

[6] DiMatteo RM. The role of effective communication with children and their families in fostering adherence to pediatric regimens. Patient Educ Couns. 2004; 55; 339-44. PMid:15582339 https://doi.org/10.1016/j.pec.2003.04.003

[7] Northouse LL, Katapodi MC, Song L, et al. Interventions With Family Caregivers of Cancer Patients: Meta-analysis of randomized trials. CA Cancer J Clin. 2010; 60: 317-39.

[8] Honea NJ, Brintnall R, Given B, et al. Putting evidence into practice: Nursing Assessment and intervention to reduce family caregiver Strain and Burden. Clin J Oncol Nurs. 2008; 12: 507-16. PMid:18515250 https://doi.org/10.1188/08. CJON . 507-516

[9] Adler NE, Page AEK. Cancer care for the whole patient: meeting psychosocial health needs. Institute of Medicine (IOM). Washington, DC: National Academies Press; 2008.

[10] Levetown M. American Academy of Pediatrics Committee on Bioethics. Communicating with children and families: from everyday interactions to skill in conveying distressing information. Pediatrics. 2008; 121: e1441-60. PMid:18450887 https://doi.org/10.154 2/peds. 2008-0565

[11] Belgacem B, Auclair C, Christ M, et al. A caregivers education program improves quality of life and burden for cancer patient and their caregivers-A randomized clinical trial. Eur J Oncol Nurs. 2013; 18: 1-7.

[12] Houts PS, Rusenas L, Simmonds MA, et al. Information Needs of Families of cancer patients A Literature Review and Recommendations. Jornal cancer Education. 2009; 6: 255-261.

[13] Zarit SH, Todd PA, Zarit JM. Subjective burden of hasband and wives as a caregivers: A longitudinal study. Gerontologist. 1986; 26(3): 260-66. https://doi.org/10.1093/geront/26.3.260
[14] McCubbin HI, McCubbin MA, Patterson JM. Coping Health Inventory for patternsin the care of the chronically Ill Child. Journal of Marriage and Family. 1983; 359-370.

[15] Amer $\mathrm{H}$. The effect of nursing intervention on reducing burden of caregivers' for children with epilpepsy. Doctorate thesis in community health nursing faculty of nursing. Meoufia University. 2015.

[16] Pahlavanzade S, Khosravi N, Moeini M. The effect of a family needbased program on burden of caregivers of leukemia patients in Isfahan in 2013-2014. Iran J Nurs Midwifery Res. 2014 Nov-Dec; 19(6): 629-634.

[17] Gazar Z, Farrage E, Thabit SH. Effectiveness of cognitive behavioral family intervention in reducing the burden of care in careers of patients with Alzhemer's diseases. The fifth international nursing conference Faculty of Nursing Menoufia University. 2017.

[18] El-Safty A. The effect of nursing intervention on traumatic stress and coping strategies among women with breast cancer. Master of thesis. Obstetric Nursing. Menoufia University. 2016.

[19] Toseland RW, Labrecque MS, Goebel ST, et al. An evaluation of a group program for spouses of frail elderly veterans. The Gerontologist. 2001; 32: 382-390. https://doi.org/10.1093/geront/3 2.3 .382

[20] Zarit SH, Reever KE, Bach-Peterson J. A stress manegement approach, in Texas. They found that interventions evaluated using the burden interview. Gerontologist. 1980; 20: 649-55. PMid:7203086

[21] Greedle C, Leak A, Deal AM, et al. The impact of education on caregiver burden on two in pationt oncology units. J Cancer Edu. 2012; 27: 250-6. PMid:22241024 https://doi.org/10.1007/ s13187-011-0302-3

[22] Asutin JK, McDermott H. Amodel of family adaptation to new-onset childhood problem comparing coping (as measured by the CHIP) to parentral attitude. Journal of Neuroscience Nursing. 2009; 28(2): 82-92.

[23] Reinhard SC, Given B, Petick NH, et al. Patient Safety and Quality: An Evidence-Based Handbook for Nurses. Supporting Family Caregivers in Providing Care. 2008.

[24] Yu Y, Hu J, Efird JT, et al. Social support, coping strategies and health-related quality of life among primary caregivers of cancer children in China. Journal of Clinical Nursing. 2013; 22: 2160-2171. PMid:23829403 https://doi.org/10.1111/jocn.12251

[25] Damrosch SP, Pert LA. Self-reported adjustment, chronic sorrow, and coping of parents of children with Down Syndrome. Nursing Research. 2007; 38: 25-30.

[26] Blount RL, Simons LE, Devine A, et al. Evidence-based assessment of coping and stress in pediatric psychology. J Ped Psych. 2008; 33: 1021-1045. PMid:17938147 https://doi.org/10.1093/jp epsy/jsm071 